\title{
O SILÊNCIO DOS JURISTAS: A IMUNIDADE TRIBUTÁRIA SOBRE TEMPLO DE QUALQUER CULTO E AS RELIGIÕES DE MATRIZ AFRICANA A LUZ DA CONSTITUIÇÃO DE 1988
}

\author{
Guilherme Martins Nascimento ${ }^{1}$ \\ Evandro Piza Duarte ${ }^{2}$ \\ Marcos Vinícius Lustosa Queiroz ${ }^{3}$
}

\begin{abstract}
Resumo
Por meio de obras doutrinárias e decisões dos tribunais superiores brasileiros, o presente artigo analisa os discursos dos juristas acerca da imunidade tributária sobre templo de qualquer culto tendo em vista as práticas de religiões de matriz africana. O material de pesquisa fora levantado a partir de busca nos sítios do Superior Tribunal de Justiça e do Supremo Tribunal Federal e em manuais jurídicos. Por meio dessa análise, procura-se compreender como o silêncio dos juristas contribui para um quadro de perpetuação das desigualdades sociais e do histórico de violência contra as expressividades negras no Brasil. A partir dessa moldura, é realizada uma reflexão sobre como essa postura jurídica distancia-se das inovações trazidas pela Constituição de 1988 no que se refere à hermenêutica jurídica. Por fim, será depreendido que o sistema decisional jurídico brasileiro ainda encontra-se marcado pela perseguição para com os negros, devendo esse contexto ser rompido, no sentido de dar visibilidade às práticas da cultura negra, quebrando o silêncio existente e efetivando as garantias constitucionais.
\end{abstract}

Palavras-chave: imunidade tributária; templos de qualquer culto; religião de matriz africana; Constituição de 1988; racismo.

\section{INTRODUÇÃO}

A promulgação da Constituição Federal de 1988 impulsionou verdadeira transformação paradigmática quanto à percepção de direitos individuais e coletivos no Brasil. Todavia, ainda que estabeleça as orientações fundamentais para dar ênfase na concretude de novos direitos, há casos em que a aplicação de normas constitucionais não se apresenta no mundo fático de forma efetiva, principalmente dentro do contexto

\footnotetext{
${ }^{1}$ Graduado em Direito pela Universidade de Brasília. Integrante do Centro de Estudos em Desigualdade e Discriminação (CEDD-UnB). E-mail: guiggas89@gmail.com

${ }^{2}$ Doutor em Direito pela Universidade de Brasília. Professor da Graduação e Pós-Graduação (Mestrado e

Doutorado) da Faculdade de Direito da Universidade de Brasília. Coordenador do Centro de Estudos em Desigualdade e Discriminação (CEDD-UnB) e do Maré: Núcleo de Estudos em Cultura Jurídica e Atlântico Negro. E-mail: evandropiza@gmail.com

${ }^{3}$ Mestrando em Direito pela Universidade de Brasília. Integrante do Centro de Estudos em Desigualdade e Discriminação (CEDD-UnB) e do Maré: Núcleo de Estudos em Cultura Jurídica e Atlântico Negro. E-mail: marcosvlq@gmail.com
} 
institucional das diversas esferas do poder executivo, legislativo e judiciário.

Novos direitos são muitas vezes "velhos novos direitos" de "velhos novos sujeitos" que, sistematicamente, foram negados e perseguidos, ao longo de toda história nacional (BERTULIO, 1989, pp. 21-23). Na trajetória constitucional brasileira, esses "sujeitos de ontem e de hoje" representam o Outro, como propôs DUSSEL (1993, pp. 185-186), consubstanciado na imagem dos povos da diáspora africana (negros) e dos povos originários das américas (indígenas). O Outro, sujeito histórico de fundamental importância para o próprio devir da construção da humanidade e dos direitos no mundo ocidental, em especial da trajetória constitucional das Américas, está envolto em representações negativas construídos pelo seu opressor e pelas práticas de opressão que negam a expansão da cidadania (DUARTE e QUEIROZ, 2016, pp. 02-05).

Nesse contexto, as expressividades de matriz africana e da diáspora negra, mesmo tendo a sua importância na própria formação plural do Brasil, integrante dos diferentes "processos civilizatórios" aqui gestados, acabam por ser preteridas no acesso a direitos. Os terreiros, os povos de santo, o Candomblé, a Umbanda, o tambor de mina, as pajelanças, a encantaria, a macumba, o batuque, as moças de branco, etc. fazem parte do cotidiano das culturas, da religiosidade e da fé existentes no país. No entanto, segundo BERTÚLIO, não é difícil procurar e perceber a grande disparidade que reina na aplicação normativa quando o caso concreto versa sobre direitos relacionados à população negra (1989, pp. 101-105). ${ }^{4}$

As religiões de matriz africana se situam em um mundo de constantes violências, tanto sociais como institucionais. A base para essas condutas encontra-se fundada na intolerância para com a simbologia e as expressividades dessas religiões, pois são representações que carregam consigo as marcas da África. São características que "se associam à língua, aos códigos comportamentais, às expressões e instrumentos musicais, às danças, à culinária e à arte de um modo geral” (IPHAN, 2012, p. 26). O povo de santo, ${ }^{5}$ portanto, é constantemente marcado por diversos ataques, uma vez que sua religiosidade faz parte das expressividades da diáspora africana.

De fato, em nossa história, o ódio às religiões negras foi uma política incentivada pelo Estado durante quase trezentos anos e foi elemento central da ideologia escravista, pois integrante da dialética do senhor (branco)

\footnotetext{
${ }^{4}$ Neste aspecto, a percepção das violações de direitos da população negra não remete somente às características fenotípicas, pois deve levar em conta uma série de estratégias discursivas e de representação que implicam em noções estratificadas do "eu" e do "outro", as quais podem ser alocadas dentro do conceito de racismo (BERTÚLIO, 1989, pp. 64-66). Assim, não se trata da ideia de raça enquanto conceito biológico e essencializado, mas enquanto dispositivo (AGAMBEN, 2009, pp. 29-33) histórico e cultural articulado politicamente (GILROY, 2012, pp. 43-44 e HALL, 2013, pp. 27-53). É neste sentido que expressividades culturais afrobrasileiras, como determinadas práticas religiosas, são alvos de violência e tratamento desigual.

${ }^{5}$ Povo de santo pode ser entendido como "as pessoas que acionam e fazem existir patrimônios expressivos nos campos da música, da dança, da arquitetura, da indumentária, da joalheria, do teatro, da alimentação e de muitos outros meios que estabelecem vínculos com esse amplo e diverso mundo cultural chamado afro, onde os terreiros funcionam como pólos produtores e mantenedores de histórias, de civilizações, de arte, de memória e de sabedoria ancestrais" (LODY, 1995, p. 01).
} 
e do escravo (negro), força motriz da história colonial (MOURA, 1988, p. 47). ${ }^{6}$ A dimensão institucional do racismo ${ }^{7}$ tornou-se a marca das relações entre Estado brasileiro e população negra. Isso se torna mais evidente quando se trata da supressão de direitos no que tange à imunidade dos templos de qualquer culto, malgrado a tutela constitucional conferida às diversas religiões existentes no país.

No passado, esse distanciamento entre texto constitucional e arcabouço jurídico-institucional era ainda mais marcante. No século XIX, essa dissociação foi, de fato, gerida e gestada como uma resposta ao fim da escravidão e a possibilidade de ascensão do negro à condição de cidadão. $\mathrm{O}$ direito serviu à inferiorização e à submissão do ser negro, ao construir a categoria do liberto que, por ser frágil diante das estratégias de reescravização de fato, situava-o entre a condição de livre e de alvo potencialmente instável. Ao mesmo tempo em que era integrante do Estado, não tinha sequer os direitos de primeira geração. Em outras palavras, enquanto houve escravidão, diante de um sistema jurídico e político conivente com essa instituição, nenhum integrante da população negra poderia se sentir efetivamente seguro de sua liberdade (DUARTE, 2011, pp. 508-511). Logo, não se pode falar em liberdade de culto para aqueles que não gozavam dessa segurança essencial.

A condição de cidadão foi ainda impedida pela institucionalização da política de embranquecimento a partir da segunda metade do século XIX, seja através da substituição dos corpos negros pelos indivíduos europeus no mundo do trabalho, ${ }^{8}$ seja por meio de constantes espoliações e privações que mantiveram a posição subalterna da população negra (FLAUZINA, 2006, pp. 55-69). Por meio de normas jurídicas, sobretudo aquelas relativas ao cotidiano e à vida nas cidades (leis de contravenção penal, posturas municipais, atribuição das polícias, etc.), consagrou-se um conjunto oficial de normas (inclusive, desde sempre, inconstitucionais), ainda vivas no período republicano, responsáveis por aumentar o mandonismo local e condenar essa população a suportar diversas formas de violência física e simbólica, particularmente em relação a suas crenças religiosas (BERTÚLIO, 1989, pp.

\footnotetext{
${ }^{6}$ Esse tratamento está presente em razão do próprio plano histórico no qual o Brasil se encontra, qual seja, um processo que prioriza a marginalização de cultos de matriz africana. Não há como negar uma suposta presença majoritária do catolicismo, em razão da adoção dessa religião como oficial durante o Império brasileiro, restringindo a prática das demais ao mundo privado, realizadas no âmbito doméstico. Além disso, importante ressaltar que havia diversas regalias, garantidas pelo próprio Estado, para com a religião católica (SABBAG, 2014, p. 329).

${ }^{7}$ A dimensão institucional do racismo não trabalha com a ideia exata de uma vítima perfeitamente definida e contrapõe-se à visão liberal do ofendido como uma identidade estritamente fechada. Assim, leva-se em conta a multiplicidade e a interseccionalidade nas quais as pessoas estão inseridas no mundo, em que a opressão estrutural se articula por arranjos coletivos operacionalizadores da distribuição desigual do poder. Como será visto no decorrer do artigo, os aspectos não-acidental e histórico desse tipo de racismo têm grande relevância. Assim, muitas vezes, implementar políticas ou disposições normativas a partir de uma postura "cega" ou neutra é uma maneira sútil de perpetuar injustiças, dando continuidade ao estado desigual das coisas (HASLANGER, 2005, pp. 119-144).

${ }^{8}$ O sistema de mão de obra escrava encontrava-se, à época, em declínio. Algumas das razões para a substituição pode ser encontrada, como propõe AZEVEDO, no medo de um levante escravo contra seus senhores e a própria dificuldade de se comercializar os corpos vindos da África. Conforme a autora, essa mudança da relação trabalhista sempre teve como base, durante as discussões parlamentares levantadas, fundamentos racistas (2004, pp. 141-166).
} 
101-105) ${ }^{9}$

Mesmo diante da previsão expressa de liberdade religiosa a todos os cultos, houve uma negação da própria possibilidade de praticar cultos de religião de matriz africana em razão do racismo institucional. No período imperial, por exemplo, o Código Criminal de 1830, em seu art. 276, punia o simples exercício de uma religião negra quando celebrado fora da máscara do catolicismo, religião oficial do Estado, pois os "cultos negros" ofenderiam, segundo os parâmetros das elites da época, os "bons costumes e a moral" (BERNARDO, 2006, p. 188).

\section{Como constata MARTON:}

É interessante enfatizar as ressalvas à liberdade de culto: "uma vez que respeite a do Estado, e não ofenda a Moral Pública" (1824); "observadas as disposições do direito comum" (1891), "desde que não contravenham à ordem pública e aos bons costumes" (1934), "observadas as disposições do direito comum, as exigências da ordem pública e dos bons costumes” (1937), "salvo o dos que contrariem a ordem pública ou os bons costumes" (1946, 1967 e 1969). Essas ressalvas podem ter consequências tributárias, eis que se discute na doutrina, para efeito de reconhecimento da imunidade tributária, a amplitude que deve ser admitida na expressão "qualquer culto" (MARTON, 2013, p. 10).

Essas ressalvas feitas em todas as Constituições anteriores poderiam ser facilmente sentidas no ordenamento infraconstitucional. Práticas institucionais de inibição da cultura negra, bem como de sujeição de indivíduos negros à esfera penal, foram atos que forneceram todo o amparo para a perseguição e discriminação jurídica. Como pode ser visto, a negação de garantias constitucionais, utilizando-se de normas infraconstitucionais e competências ordinárias como modelo de aplicação, foi prática constante na história da ordem constitucional pátria.

Nota-se que essa inter-relação entre normas supostamente abstratas, que não se dirigem especificamente à população negra, com práticas institucionais cotidianas de violências contra às religiões de matriz africana, coaduna-se perfeitamente com a ideologia da democracia racial. Como aponta SOVIK, tal ideologia, junto com o discurso da mestiçagem, procura criar zonas do indizível sobre as relações e desigualdades raciais no Brasil. Aqui, todo mundo seria "mestiço" ou simplesmente "brasileiro. Afasta-se, assim, da discussão pública a problematização do padrão branco como ordenador das estruturas de poder na sociedade brasileira (2004, p. 371).

Esse discurso oficial (NASCIMENTO, 1978, pp. 41-47), ao retratar um Brasil sem tensões raciais, harmonioso e pacífico, impede a emergência de narrativas alternativas sobre a história nacional e sobre outros padrões de justiça, contribuindo para a manutenção da colonialidade no presente. Essa é percebida na

\footnotetext{
${ }^{9}$ BOURDIEU aborda o papel das normas jurídicas, que, por meio do seu efeito de universalização, atuam como mecanismo de dominação simbólica e de legitimação de uma determinada ordem social. Sob a abstração e a universalidade, o direito, enquanto conjunto formalmente coerente de regras oficiais, consagra o estilo de vida simbolicamente dominante, informando as práticas cotidianas do conjunto dos agentes sociais. Assim, pela promoção ontológica de transformar certa regularidade em regra geral, impõe uma normalidade em relação à qual todas os hábitos diferentes se colocam como anormais, desviantes e até mesmo patológicos, passíveis de perseguição e "jurisdicização" (2010, p. 245).
} 
continuidade de estruturas extremamente desiguais de poder no que se refere a raça, gênero, sexualidade e classe (BERNARDINO-COSTA, 2015, p. 27). Portanto, ao invisibilizar e silenciar a presença negra por meio dos artifícios da universalidade e da abstração, afastando a percepção de uma história de violações e negações que tem raiz na estrutura do complexo colonial (FANON, 2008, pp. 33-34), o discurso jurídico serve de legitimação ao estado desigual das coisas e de freio aos anseios de democratização. Onde há discriminação negativa, o ato de nomeá-la é imprescindível para sua superação.

Nesse contexto, o presente artigo pretende cumprir duas tarefas. Primeiramente, tendo em vista que o sistema normativo é moldado por práticas acadêmicas e decisões do poder judiciário, intenta, por meio da análise de discursos doutrinários e judiciais, demonstrar como a imunidade tributária é discutida pelos juristas nos tribunais e na academia. A partir disso, aborda como o tom universalista desses discursos exclui, de modo inconstitucional, templos que remetam às religiões de matriz africana. Em um segundo momento, coloca em destaque a tradição colonial sob a qual se escora o pensamento jurídico hegemônico, na medida em que ela não historiciza ou problematiza o fenômeno do racismo como balizador das práticas institucionais dirigidas às expressividades negras, mesmo quando o Estado é identificado como um dos perpetradores dessas violações.

\section{AS BASES DO SILENCIO: OS DISCURSOS DA DOUTRINA JURÍDICA SOBRE A IMUNIDADE TRIBUTÁRIA DE TEMPLOS DE QUALQUER CULTO}

O discurso contido nos manuais de direito é um dos pilares da formação do pensamento jurídico no ensino superior do país, estando também presente na fundamentação das decisões do poder judiciário. O manual jurídico acaba por reproduzir determinadas interpretações e aplicações de normas jurídicas e, sobretudo, ensina um modo de considerar a realidade, marcando simbolicamente o que é relevante, o que deve ser negado socialmente, as permissões e interdições de um discurso tido como válido, ou melhor, jurídico. E neste caso há uma distinção sutil, mas importante. Os manuais treinam seu leitor não apenas para aceitarem determinado argumento, mas, sobretudo, induzem-no a aceitar que determinada forma de argumento não pode ser utilizada como juridicamente válida. Os exemplos, os problemas, os casos relevantes e as referências à história e à realidade são filtros ideológicos essenciais da formação, condicionando o aprendizado de valores e posturas diante de situações futuras. (DUARTE, 1998, pp. 12-15; FOUCAULT, 2006, pp. 09-21).

Como seria possível identificar os manuais de direito tributário mais relevantes na formação dos juristas? O tema vem sendo debatido em alguns trabalhos. Poder-se-ia utilizar, por exemplo, os programas de disciplinas existentes nos cursos jurídicos (públicos, privados, mais conceituados, etc.), a ocorrência em buscas de bibliotecas especializadas (tribunais superiores, órgãos de classe, etc.), a referência feita pelos operadores jurídicos (advogados, promotores, defensores, juízes, etc.) a determinados autores, a indicação dada por um grupo 
específico (professores renomados, integrantes de determinado instituto de pesquisa), padrões de consumo no mercado editorial ou em um grupo restrito de editoras, entre outros. Cada uma dessas opções possui seus limites, suas peculiaridades e corresponde a determinada finalidade. (DUARTE, 1998, pp. 31-32).

De qualquer forma, é preciso considerar que, ao tratarem de direito tributário, no que se refere a imunidades tributárias, o Supremo Tribunal Federal e o Superior Tribunal de Justiça dão uma significativa importância a determinados títulos, ante a quantidade de citações realizadas em seus respectivos acórdãos. Logo, tendo em vista que o problema tratado neste texto é bem específico e se pretende observar os padrões de decisão judicial, optou-se por uma análise prévia dos acórdãos desses tribunais a partir de pesquisa realizada nos respectivos sítios eletrônicos utilizando como argumento de pesquisa “imunidade de templos". Desse conjunto, identificamos a "doutrina majoritária" sobre o tema. ${ }^{10}$

A cobrança tributária goza de papel central na estruturação do Estado, tendo em vista que é por meio dela que serviços essenciais são disponibilizados (AMARO, 2011, pp. 39-40; e CARRAZZA, 2010, pp. 513-514). No entanto, esse poder de tributar é limitado pelo ordenamento, tendo o instituto da imunidade tributária como um dos mecanismos dessa autocontenção. Nele, é limitado o lastro de tributação estatal com vistas à valorização e proteção de liberdades abarcadas constitucionalmente, entre elas a liberdade de religião (CÔELHO, 2009. p. 265).

A imunidade tributária em questão apenas tomou essa forma na Constituição de 1946. Até então, não se vislumbrava o alargamento da imunidade a todas as religiões, mesmo sendo adotada uma suposta laicidade estatal, uma vez que a expressão "templos de qualquer culto" não existia (MARTON, 2013, pp. 11-12). As Constituições posteriores adotaram a mesma expressão, chegando até a atual, em que se verifica um tratamento próprio a respeito de cultos religiosos, expresso no art. 5\%, VI a VIII. Diante de uma necessidade de se convencionar uma inviolabilidade e a liberdade de crença, além de reforçar a laicidade estatal, a imunidade tributária sobre templos de qualquer culto apresenta-se como garantia para plena efetivação do exercício religioso, independentemente do culto (SABBAG, 2014, p. 330).

Segundo a doutrina majoritária, a aplicação do instituto deve levar em conta a entidade mantenedora do templo religioso, desonerando os impostos que recaiam sobre patrimônio, renda e serviços relacionados às finalidades das instituições religiosas (SABBAG, 2014, p. 334; COSTA, 2001, p. 159). Neste sentido, a falta de acesso de um grupo de religióes à essa garantia resulta, na prática, em ônus maior para sua sobrevivência, bem

\footnotetext{
${ }^{10}$ Para a realização do presente artigo, optou-se por uma análise de acórdãos dos tribunais superiores a partir de pesquisa realizada nos próprios sítios eletrônicos, utilizando como argumento de pesquisa "imunidade templos". Coletamos um total de 16 acórdãos no STF e 7 acórdãos no STJ. Desse total, depurado o argumento pela leitura dos conteúdos, ficamos apenas com 13, tendo em vista a própria argumentação utilizada na deliberação acerca do objeto presente nos casos, qual seja, a imunidade tributária sobre templos de qualquer culto. Desse conjunto, foram selecionados os autores que se faziam presentes nas fundamentações jurídicas dos Ministros, totalizando 11 juristas.
} 
como um grave risco à liberdade religiosa, podendo implicar, inclusive, na ausência de condições financeiras para continuidade da atividade. ${ }^{11}$

Tratando especificamente do discurso contido nos manuais de direito, percebe-se que nas principais obras contemporâneas há como padrão um silêncio sobre as religiões de matriz africana. Existe, assim, uma evidente perpetuação da reprodução de um contexto jurídico voltado para a valoração de determinadas religiões e, paralelamente, a exclusão de outras. Neste sentido, poucos doutrinadores se debruçam a respeito da garantia sobre templos, pois, para eles, a simples expressão "qualquer culto" já abrange a liberdade religiosa como um todo.

Como regra, a doutrina majoritária coloca a necessidade dessa imunidade tributária como uma forma de assegurar a liberdade religiosa, de modo a facilitar a manifestação de religiões livremente, sem constrangimentos estatais e privados. No entanto, apesar dessa ampla aceitação, o conjunto de aplicação normativa para esses juristas se encontra vinculada apenas a algumas religiões e não a todas. Basta observarmos os tipos de entidades citadas para que se perceba a existência de uma interdição (fundada num esquecimento injustificável) em relação às religiões de matriz africana (BASTOS, 2001, p. 132; CARRAZZA, 2010, p. 786; CARVALHO, 2009, p. 684; COSTA, 2001, pp. 156-157; MENDES, 2011, pp. 1483-1484; SABBAG, 2014, pp. 337-339; TORRES, 2010, p. $74)$.

CARRAZZA, ao tratar do tema, aponta que a imunidade tributária sobre templos deve ser interpretada amplamente, assim como o próprio conceito de templo. Todavia, essas interpretações carregam consigo somente expressões que remetem a um conjunto específico de religiões, quais sejam, o catolicismo e os cultos evangélicos. Para ele,

Mais que templo propriamente dito - isto é, o local destinado a cerimônias religiosas -, o benefício alcança a própria entidade mantenedora (a Igreja), além de se estender a tudo quanto vinculado às liturgias (batizados, celebrações religiosas, vigílias, etc.) (CARRAZZA, 2010, p. 786).

Em outro momento, o autor fala em presunção a priori das religiões, em que todas são legítimas, porém, em seguida, diz ser necessário o atendimento de requisitos mínimos de espiritualidade e transcendentalidade. Além disso, refere-se explicitamente às comunidades judaicas e muçulmanas, consideradas semelhantes à religião católica e evangélica por terem uma fé comum (CARRAZZA, 2010, p. 802). No entanto, nada se fala a respeito de outras religiões, principalmente no que se refere as de matriz africana.

Embora não seja uma orientação pacificada, esse posicionamento possui amplo lastro entre os juristas, em que a grande maioria segue a mesma linha: dar uma grande abrangência da aplicação da imunidade tributária sobre templos para, logo em seguida, ressaltar algumas religiões enquanto silencia e apaga outras (justamente

\footnotetext{
${ }^{11}$ Por outro lado, nota-se uma expansão cada vez maior de segmentos religiosos que exploram a dimensão econômica das práticas religiosas, em que os campos da fé e do empreendedorismo se interrelacionam sobre uma zona ainda fluída no que tange a aplicação normativa (veja-se, por exemplo: MARIANO, 2011; SOUZA 2013).
} 
aquelas perseguidas na história constitucional brasileira).

Para MACHADO, a imunidade tributária sobre templos abarca "missas, batizados ou qualquer outro ato religioso. [...] Mas, pode incidir imposto sobre bens pertencentes à Igreja, desde que não sejam instrumentos desta" (2011, p. 289). SABBAG apresenta um grande leque de possibilidade de reconhecimento, porém, ao exemplificar a amplitude da garantia constitucional, utiliza-se de exemplos que remetam à religião católica por meio de termos como Igreja e dízimos (SABBAG, 2014, pp. 337-339).

COSTA afirma que o patrimônio, a renda e os serviços, objetos da imunidade em questão, dizem respeito às finalidades essenciais da própria igreja (COSTA, 2001, p. 158). MORAES acrescenta que o instituto alcança não só os imóveis para realização do culto, mas também aqueles que estejam relacionados com a atividade essencial, a exemplo dos seminários, as sacristias e a residência oficial dos ministros religiosos (MORAES, 2008, p. 869). Da lição de MEIRELLES, retira-se o entendimento de que apenas as igrejas possuem o direito a esse benefício, uma vez que são consideradas como templos onde se realizam cultos religiosos (MEIRELLES, 1998, p. 172). Nota-se, assim, que em todos esses autores há o estabelecimento da igreja como grande símbolo de templo religioso.

Enquanto esses últimos autores mostram-se preocupados com uma delimitação do que deveria receber a garantia de imunidade, há outros que se valem de descrições universais em razão da existência de uma norma abstrata. É o caso de MENDES ao tratar do instituto como um instrumento que visa assegurar a liberdade religiosa, colocando o templo como "local onde se pratica toda a manifestação organizada de religiosidade, ainda que não seja um prédio. A proteção é válida para qualquer religião licitamente praticada” (2011, p. 1483). De outro modo, AMARO (2011, p. 179) não chega a se debruçar sobre a imunidade tributária sobre templos religiosos em si, posto que apenas faz menção ao dispositivo constitucional.

Em contraste a esses autores, há tão somente uma única vertente doutrinária que, de fato, amplia a abrangência da imunidade tributária, fugindo de possíveis restrições mínimas que remetam às religiões católica e evangélica. COÊLHO, à exceção dos cultos que geram abuso da religião, ${ }^{12}$ afirma que templo:

não é só a catedral católica, mas a sinagoga, a casa espírita kardecista, o terreiro de candomblé ou de umbanda, a igreja protestante, shintoísta ou budista e a mesquita maometana. Pouco importa tenha a seita poucos adeptos. Desde que uns na sociedade possuam fé comum e se reúnam em lugar dedicado exclusivamente ao culto da sua predileção, este lugar há de ser um templo e gozará de imunidade tributária. [...]. Imune é o templo, não a ordem religiosa. Esta pode gozar de isenções quanto a seus bens, rendas, serviços, indústrias e atividades, se pias, caritativas, filantrópicas (COÊLHO, 2009, p. 269).

Encontramos, portanto, certo padrão nos manuais passados para a formação jurídica. Trata-se de uma orientação que tende, paradoxalmente, a ampliar o rol de garantias e direitos ao passo que é silente em relação ao

\footnotetext{
${ }^{12}$ Aqui a autora aponta os casos de abuso que acabam dando ensejo ao poder de polícia com intuito de findar os atos considerados religiosos. Ela entende por abuso os sacrifícios humanos ou fanatismo visionário, além da prática de comércio, com animus
} 
acesso nesses mesmos direitos por grupos historicamente marginalizados e perseguidos. São justamente esses grupos os mais interessados não só na proteção tributária, mas também em uma mudança efetiva da posição histórica do Estado como agente perpetrador de violências contra as expressividades da diáspora africana.

Assim, além da doutrina majoritária entender que os templos estão sempre ligados a um modelo de religião cuja liturgia está pautada nas igrejas católica e evangélica, o problema se apresenta de maneira mais profunda. Pois a ausência de menções às religiões de matriz africana ocorre justamente em um contexto constitucional que exige um compromisso jurídico e institucional ativo perante os grupos historicamente marginalizados e perseguidos pelo Estado brasileiro, dando efetividade ao pluralismo e à memória constitucional consagrados no texto magno de 1988 (DUARTE, 2011, pp. 68-69).

Essa construção doutrinária hegemônica acaba legitimando e instrumentalizando a aplicação do direito, fazendo com que se utilize uma base argumentativa que nega, silencia ou afasta garantias às religiões dos povos de santo.

\section{A LEGITIMAÇÃO DO SILÊNCIO: PODER JUDICIÁRIO E A CAPACIDADE DE MARGINALIZAR}

O poder judiciário detém importante função de estabilização do discurso jurídico, pois, enquanto esfera de imposição por meio da autoridade (DERRIDA, 2010, pp. 81-82), realiza atos de nomeação e de instituição que legitimam a atuação estatal e homogeneízam as estruturas fáticas, reduzindo, no plano simbólico (e de maneira violenta), a complexidade das relações sociais (BOURDIEU, 2010, p. 237).

Assim, do mesmo modo que foi verificado na doutrina, as decisões dos órgãos superiores do judiciário, quanto ao tema de imunidade tributária sobre templos, evidenciam um silêncio atinente às religiões de matriz africana. Isso se dá, em grande medida, pelo próprio uso de uma doutrina jurídica que é omissa ao tratar dessa questão.

No Recurso Extraordinário 325.822-2/SP, por exemplo, de relatoria do Ministro Ilmar Galvão, foi abordada a questão do reconhecimento da imunidade tributária sobre templos a determinados imóveis, tratando da extensão da garantia constitucional a outros bens onde não se realizam os cultos propriamente ditos. No caso, figuravam como recorrentes uma diocese e três paróquias (BRASIL, 2004, p. 23).

$\mathrm{Na}$ fundamentação apresentada pela relatoria, foram utilizadas as argumentações dos doutrinadores Hugo de Brito Machado, Aliomar Baleeiro, Hely Lopes Meirelles e Sacha Calmon Navarro Côelho, para delimitar o campo ampliativo da imunidade em questão. Entendeu o Ministro Ilmar Galvão que a imunidade não poderia ser estendida a outros bens imóveis vinculados indiretamente às mitras e às paróquias, posto que não se exerciam 
ali atividades essenciais à prática do culto religioso (BRASIL, 2004, pp. 7-10).

O Ministro Gilmar Mendes divergiu do relator, fazendo uso do pensamento de Roque Antonio Carrazza e Ives Gandra Martins, além de reforçar a orientação de Hugo de Brito Machado e Aliomar Baleeiro. Para ele, verifica-se que, por uma lógica de equiparação dada pelo $₫ 4^{\circ}$ do art. 150 da CF, todos os bens imóveis colocados como objeto da lide deveriam receber a imunidade tributária, uma vez que é garantida a aplicação do instituto sobre o patrimônio, renda e serviços dos templos religiosos (BRASIL, 2004, p. 13-19).

Desse modo, a garantia constitucional seria aplicada quando se aferir que determinados espaços, por exemplo, se destinam a finalidades essenciais da entidade religiosa. Seguindo esse pensamento, diversos julgados, tanto do STJ, quanto STF, também apontaram que a extensão da imunidade tributária sobre templos é um instituto que deve ser interpretado de forma ampla, de modo que alcance bens vinculados indiretamente ao culto. ${ }^{13}$

Outro caso de relevância, tendo como consequência a própria discussão acerca da definição jurídica de templo e de culto religioso, é o julgamento do Recurso Extraordinário 562.351/RS, que teve como relator o Ministro Ricardo Lewandowski. Em síntese, a controvérsia girava em torno da possibilidade, ou não, da aplicação da garantia constitucional nos espaços em que se desenvolvia a maçonaria (BRASIL, 2012, p. 37). ${ }^{14}$

Em sua fundamentação, o Ministro Ricardo Lewandowski, para saber se a maçonaria é alcançada pela garantia constitucional da imunidade tributária, utiliza a doutrina de Sacha Calmon Navarro Côelho e, principalmente, Roque Antonio Carrazza. O Ministro afirmou que o dispositivo constitucional em questão, art. 150, VI, $b$, deve ser interpretado de forma restritiva. ${ }^{15}$ Assim, a imunidade tributária se encontraria limitada a lugares nos quais se exerçam cultos religiosos, como propõe o segundo doutrinador citado. Porém, discordando desse último, o Ministro Ricardo Lewandowski considerou a maçonaria mais como uma filosofia de vida do que como uma religião (BRASIL, 2012, pp. 9-14).

Além disso, nos termos dos acórdãos relacionados, a comprovação de que determinado imóvel estaria ou não exercendo a atividade essencial da entidade religiosa deveria ser feita pela própria Administração Pública

\footnotetext{
${ }^{13}$ Ver também os seguintes julgados: STF - RE no 578.562-9/BA, Rel. Min. Eros Grau, Tribunal Pleno, DJe de 11 set. 2008; STF AgR no AI no 690.712-8/RJ, Rel. Min. Ricardo Lewandowski, Primeira Turma, DJe de 13 ago. 2009; STF - AgR no RE nº 658.080/SP, Rel. Min. Luiz Fux, Primeira Turma, DJe de 14 fev. 2012; STF - AgR no AI no 651.138-1/RJ, Rel. Min. Eros Grau, Segunda Turma, DJe de 16 ago. 2007; STF - AgR no AI no 595.479/SC, Rel. Min. Ayres Britto, Primeira Turma, DJe de 05 ago. 2010; STJ - AgR no AREsp no 671.921/RJ, Rel. Min. Assusete Magalhães, Segunda Turma, DJe de 01 jul. 2015.

${ }^{14}$ Dentre todos os julgados levantados, o Recurso Extraordinário 562.351/RS foi o único que se debruçou acerca do conceito de culto para fins de enquadramento ou não de templos à hipótese de imunidade tributária.

${ }^{15}$ A exegese a ser utilizada no aspecto restritivo dado pelo Ministro diz respeito à limitação de patrimônio, renda e serviços ligados às finalidades essenciais da entidade religiosa, ou seja, a restrição diz respeito às esferas religiosas. A interpretação que é utilizada nos julgados, supostamente, é sempre extensiva, em consonância com a liberdade religiosa preconizada no art. $5^{\circ}$ da Constituição Federal.
} 
do ente político em que se situa o bem. ${ }^{16}$ Como se percebe, não se trata de garantir os direitos constitucionais, em que o particular poderia atestar as finalidades essenciais, mas sim de deixar aberta a possibilidade de arbitrariedade por parte de um Estado que ainda persegue a população negra em diversos âmbitos sociais, especialmente quando se constata a fragilidade do modelo de Estado laico no país. ${ }^{17}$

$\mathrm{Da}$ análise desses julgados, constatamos algumas constantes que merecem consideração. Em primeiro lugar, nenhum acórdão teve como polo algum templo de matriz africana. Tanto o STF quanto o STJ buscaram solucionar conflitos jurídicos envolvendo templos de religiões cristãs. Em segundo lugar, utilizam-se vastamente da doutrina jurídica que mantém uma omissão acerca das religiões de matriz africana.

Portanto, mesmo com a predominância da vedação de tributar "templos de qualquer culto", prevista no art. 150, VI, b, da Constituição, a jurisprudência, ao ter a doutrina como grande elemento de fundamentação das decisões, acaba por dar continuidade ao quadro de silenciamento e apagamento da presença das religiões de matriz africana no país. Ratificando um histórico de violência e exclusão, discursos doutrinários e judiciários entrelaçam-se de modo a perpetuar uma posição subalterna das expressividades negras, enfraquecendo as garantias constitucionais e o princípio do pluralismo cultural e político.

\section{UMA HERMENEUTICA QUE LEVE O PLURALISMO A SÉRIO: RECONHECIMENTO COMO MEIO PARA PERCEPÇÃO DE DIREITOS}

Durante toda a história do Brasil, as práticas dos cultos de matriz africana tiveram papel importante não só na constituição de uma comunidade afro-brasileira, mas também na articulação ampla de grupos oriundos da África, na catalização de movimentos políticos e no fornecimento de assistência básica para diversos segmentos populacionais (PARÉS, 2007, p. 128). Mesmo com os ataques e violências perpetrados por grupos privados ou pelo poder público, essas expressividades deixaram um legado vivo de valores, laços de solidariedade e princípios socialmente internalizados pela sociedade brasileira (IPHAN, 2012, p. 26).

Foi a partir justamente dessa concepção mais ampla dos povos de santo que iniciativas e movimentos sociais, da década de 70 em diante, colocaram na arena política a necessidade do reconhecimento de direitos já

\footnotetext{
${ }^{16}$ Ver os seguintes julgados: STF - AgR no RE no 841.212/RJ, Rel. Min. Luiz Fux, Primeira Turma, DJe de 05 dez. 2014; STF AgR no ARE no 788.666/RJ, Rel. Min. Roberto Barroso, Primeira Turma, DJe de 06 mar. 2015; STF - AgR no ARE nº 800.395/ES, Rel. Min. Roberto Barroso, Primeira Turma, DJe de 13 nov. 2014; STJ - AgR no AREsp no 444.193/RS, Rel. Min. Mauro Campbell, Segunda Turma, DJe de 10 out. 2014; STJ - AgR no AREsp no 417.964/ES, Rel. Min. Herman Benjamin, Segunda Turma, DJe de 15 abr. 2014.

${ }^{17}$ No Distrito Federal, por exemplo, diversas práticas institucionais encontraram-se alicerçadas em fundamentos racistas. Por meio de interdições e da cobrança seletiva do "habite-se", a Agência de Fiscalização do Distrito Federal (Agefis), até 2012, conseguiu fechar diversas casas de religião de matriz africana. Embora haja previsão legal dessa exigência, diversos templos irregulares, que não são de religiões afro-brasileiras e que se situam na mesma região dos terreiros, acabam por não sofrer o mesmo processo de cobrança. Ver em: <http/:cartamaior.com.br/?/Editoria/Politica/Perseguicao-institucional-aos-terreiros-do-DF-pode-acabarnesta-segunda-\%0d\%0a/4/24681>. Acesso em: 20 maio. 2015.
} 
previstos na Constituição da época (GUIMARÃES, 2014, p. 48). É em decorrência dessas lutas que hoje verificamos que o Estado brasileiro tem buscado, minimamente, reorientar suas ações institucionais com vistas a combater o racismo e a promover o pluralismo social (IPHAN, 2012, pp. 56-57). Neste contexto, a Constituição de 1988 surge e serve como eixo essencial para articular todo um novo campo de disputa política e jurídica, pois foi através dela que expressões, nunca antes tratadas pelo ordenamento jurídico brasileiro, chegaram a ser expressamente mencionadas.

Como aponta DUARTE, ao abordar os artigos $215^{18}$ e $216^{19}$ do texto constitucional, a Constituição de 1988 estabelece uma noção de patrimônio brasileiro que não é definido pela busca da identidade homogênea de uma suposta brasilidade. Pelo contrário, é rechaçado um modelo simplista, individualista, binário ou de uma cultura oficial, passando ao reconhecimento do pluralismo das instituições promotoras de cultura, as quais não podem ser subsumidas nas matrizes culturais dominantes (2011, p. 223).

Ademais, o texto constitucional, como expresso nos artigos citados, traz com ele uma concepção de "memória constitucional", em que a própria ideia de Constituição é ampliada. Assim, ela passa a expressar uma história de longa duração da qual o contemporâneo (o tempo presente) é parte (a presença das noções de quilombos, sítios arqueológicos, diversos participantes do processo civilizatório nacional, etc. evidenciam essa perspectiva).

Diante disso, é preciso ler a Constituição a partir dessas narrativas, experiências e vivências que foram historicamente negadas, excluídas, apagadas, silenciadas e violentadas, o que significa realizar uma hermenêutica constitucional que enxergue os direitos constitucionais não como a-históricos ou abstratamente "dados", mas sim como frutos de lutas diversas, entre as quais as travadas pelos povos de santo.

A "memória constitucional", portanto, é elemento que historiciza a Constituição e os próprios direitos, evitando anacronismos interpretativos, travestidos de silêncios e omissões, que representam um Brasil contemporâneo irreal, simplificado e homogeneizado, muito mais condizente com as antigas visões e projetos coloniais das elites senhorias de um passado nem tão distante, em que religião é sinônimo de cristianismo e a expressividade negra não faz parte da "paisagem nacional". ${ }^{20}$

\footnotetext{
${ }^{18}$ Art. 215. O Estado garantirá a todos o pleno exercício dos direitos culturais e acesso às fontes da cultura nacional, e apoiará e incentivará a valorização e a difusão das manifestações culturais. $\$ 1^{\circ}$ - O Estado protegerá as manifestações das culturas populares, indígenas e afro-brasileiras, e das de outros grupos participantes do processo civilizatório nacional; $₫ 2^{\circ}$ - A lei disporá sobre a fixação de datas comemorativas de alta significação para os diferentes segmentos étnicos nacionais.

${ }^{19}$ Art. 216. Constituem patrimônio cultural brasileiro os bens de natureza material e imaterial, tomados individualmente ou em conjunto, portadores de referência à identidade, à ação, à memória dos diferentes grupos formadores da sociedade brasileira, nos quais se incluem: I - as formas de expressão; II - os modos de criar, fazer e viver; III - as criações científicas, artísticas e tecnológicas; IV - as obras, objetos, documentos, edificações e demais espaços destinados às manifestações artístico-culturais; V - os conjuntos urbanos e sítios de valor histórico, paisagístico, artístico, arqueológico, paleontológico, ecológico e científico.

${ }^{20} \mathrm{O}$ retrato máximo dessa ignorância e permanência colonial pode ser identificada em decisão do juiz federal da 17a Vara Federal do Rio de Janeiro. Nela, o magistrado defendeu tese absurda segundo a qual as manifestações religiosas de matriz africana não
} 
Assim, a Constituição, em uma sociedade evidentemente precária quanto ao reconhecimento de direitos aos grupos "minoritários" e ainda permeada pela prática do racismo institucional, exige uma postura ativa da hermenêutica jurídica no que se refere à proteção e à efetivação dos direitos dos grupos historicamente subalternizados.

A previsão constitucional de normas que enunciam esses "novos sujeitos constitucionais" deve vir, então, acompanhada de uma exegese do princípio da igualdade ligada ao direito à diferença. Significa interpretar o direito como um processo que busque agregar concepções de igualdade formal e material, de modo a fortalecer arranjos institucionais-coletivos orientados para o reconhecimento e não mais para a exclusão (DUARTE; CARVALHO NETO, 2012, pp. 53-54).

Em consequência, dá-se ênfase a uma hermenêutica jurídica atenta à contemporaneidade, em que novos sujeitos e demandas habitam a esfera pública para recompô-la estruturalmente. Não almejam a ordem, mas outras ordens diversas e plurais. "A diferença, nesse caso, não é apenas o que se pretende corrigir com políticas de desigualdade, mas aquilo que se pretende ver manifestado como forma também constitutiva da vida social" (DUARTE, 2011, p. 86).

Tal interpretação constitucional coaduna-se com o próprio conteúdo jurídico do princípio da igualdade. A igualdade é princípio que tem como núcleo dois objetivos principais: por um lado, propiciar a garantia individual contra perseguições e, de outro, tolher favoritismos. Relaciona-se também com o ideal de isonomia, ou seja, que sejam tratadas igualmente as situações iguais e desigualmente as situações desiguais (MELLO, 2010, pp. 24-35).

Neste sentido, como coloca Celso Antônio Bandeira de Mello, qualquer discrímen jurídico, para que não fira a isonomia, deve respeitar determinados elementos, quais sejam:

a) que a desequiparação não atinja de modo atual e absoluto um só indivíduo; b) que as situações ou pessoas desequiparadas pela regra de direito sejam efetivamente distintas entre si, vale dizer, possuam características, traços, nela residentes, diferençados; c) que exista, em abstrato, uma correlação lógica entre os fatores diferenciais existentes e a distinção de regime jurídico em função deles, estabelecida pela norma jurídica; d) que, in concreto, o vínculo de correlação supra-referido seja pertinente em função dos interesses constitucionalmente protegidos, isto é, resulte em diferenciação de tratamento jurídico fundada em razão valiosa - ao lume do texto constitucional - para o bem público (MELLO, 2010, p. 41).

Esses elementos são complexificados a partir do redimensionamento colocado pela relação entre igualdade e diferença, sobretudo em uma situação em que o reconhecimento da humanidade e dos direitos de grupos excluídos funda-se num desconhecimento dos privilégios por diversos outros grupos sociais. Nestes contextos, o processo de construção de direitos pelos subalternizados é visto como uma perda de direitos pelos

detém traços essenciais que formam uma religião de fato, portanto não se constituindo como tal. Justiça Federal. 17a Vara Federal do Rio de Janeiro. Sentença de $1^{\circ}$ Grau da Ação Civil Pública no 0004747-33.2014.4.02.5101. Disponível em: <http://www.migalhas.com.br/arquivos/2014/5/art20140519-06.pdf>. Acesso em 20 maio 2015. 
setores hegemônicos, como um benefício desarrazoado ou, então, como uma ação violenta perante a ordem das coisas (DUARTE, 2011, p. 183). Neste sentido, necessita-se de uma concepção de igualdade mais profunda, como na síntese proposta pela professora Flávia Piovesan:

a) a igualdade formal, reduzida à fórmula "todos são iguais perante a lei (que, ao seu tempo, foi crucial para a abolição de privilégios); b) a igualdade material, correspondente ao ideal de justiça social e distributiva (igualdade orientada pelo critério sócio-econômico); e c) a igualdade material, correspondente ao ideal de justiça enquanto reconhecimento de identidades (igualdade orientada pelos critérios de gênero, orientação sexual, idade, raça, etnia e demais critérios) (PIOVESAN, 2010, p. 03).

Nesta acepção do princípio da igualdade, não bastam apenas a redistribuição mais equânime de riquezas e o enfrentamento da injustiça econômica. Faz-se necessário a percepção de que o direito ao reconhecimento "requer medidas de enfrentamento da injustiça cultural, dos preconceitos e dos padrões discriminatórios, por meio da transformação cultural e da adoção de uma política de reconhecimento." Assim, para o avançar da reavaliação positiva das identidades e das representações de grupos historicamente marginalizados, discriminados, negados e violentados, é exigida a desconstrução de estereótipos e preconceitos e a valorização da diversidade cultural, conforme o estabelecido pela própria Constituição de 1988 (PIOVESAN, 2010, pp. 03-04).

A partir dessas noções, evidencia-se que não só inexiste um critério de discrímen legítimo para diferenciar e privilegiar a religião católica e evangélica em relação às religiões de matriz africana no tocante à imunidade tributária - entendimento contrariado pelo silêncio dos juristas, conforme argumentado ao longo desse artigo. Pelo contrário, ao enraizar o princípio da igualdade na memória constitucional e na valorização da diferença e da diversidade, a Constituição de 1988 estabeleceu compromissos jurídicos a serem observados pelos operadores do direito.

Nesse sentido, a leitura dos princípios e objetivos constitucionais deve ser feita à luz do histórico de discriminação, perseguição e exclusão contra determinados segmentos sociais, tendo em vista, sobretudo, a participação do Estado brasileiro como um dos principais perpetradores dessas violências. Abre-se, portanto, a possibilidade de uma hermenêutica e de uma prática constitucional do princípio da igualdade que, tirando da penumbra e do silêncio as religiões de matriz africana, busquem medidas afirmativas e positivas de proteção dessas expressividades negras no Brasil.

É esse tipo de percepção do princípio da igualdade ligado à diferença que pode ser percebido em ações recentes adotadas pelo Estado brasileiro, como o I Plano Nacional de Desenvolvimento Sustentável dos Povos e Comunidades Tradicionais de Matriz Africana e o mapeamento dos locais onde há o exercício de culto de matriz africana como resultado do Inventário Nacional de Referências Culturais (INRC), consagrando o terreiro como um templo religioso no aspecto regional (GUIMARÃES, 2014, p. 46). Por meio de políticas de reconhecimento, criam-se, assim, instrumentos necessários para confrontar as constantes discriminações e violências perpetradas contra as expressividades negras no país. 
No entanto, toda essa dinâmica, que vem ocorrendo na esfera pública brasileira e no âmbito institucional, ainda parece não ter alcançado os palácios de mármore do direito, os quais mantêm-se encastelados à pluralidade e às expressividades da diáspora negra existentes no Brasil, mesmo com as mudanças profundas e sensíveis trazidas pela Constituição de 1988. Evidencia-se, portanto, a necessidade sempre premente de abertura do direito perante a realidade histórica, sob pena do silêncio dos juristas, expresso nos manuais e decisões judiciais, continuar a ser fundamento de continuidade das relações desiguais e coloniais reatualizadas no presente.

\section{CONCLUSÃO}

O presente artigo apresentou o discurso dos juristas, na doutrina e na jurisprudência, no que se refere à garantia da imunidade tributária sobre templo de qualquer culto, tendo como recorte as expressividades religiosas de matriz africana. Como pôde ser visto, as narrativas hegemônicas compartilham de um profundo silêncio a respeito dos povos de santo, retratando um Brasil no qual o catolicismo ou o neopentecostalismo aparecem como únicas realidades possíveis, quando não param em posicionamentos abstratos e universalistas que nada dizem. Essa visão se torna mais problemática diante do histórico de violações perpetradas contra as manifestações da diáspora africana no Brasil, sobretudo aquelas cometidas pelo próprio Estado brasileiro. Justamente as religiões que mais necessitam de uma maior proteção jurídica são aquelas apagadas, silenciadas e excluídas do discurso dos juristas.

Percebe-se, portanto, o descompasso do debate no âmbito do direito tributário diante das demandas, movimentos e complexidade da realidade brasileira, não acompanhando, sequer, as inovações e a perspectiva trazidas pela Constituição de 1988. Essa, por meio da memória constitucional, procurou historicizar o direito e colocar o presente como parte de uma história de longa duração, em que as violências, lutas, exclusões e narrativas do passado expressam-se na contemporaneidade e exigem uma postura do Estado, do ordenamento jurídico e de seus respectivos operadores.

Ratificando uma determinada ordem como única possível, vinculada a um tipo de história oficial com raízes no passado colonial, em que a cruz e a espada foram os símbolos da opressão contra os povos originários e da diáspora africana, a doutrina e a jurisprudência brasileiras, em relação às imunidades tributárias sobre os templos religiosos, afastam-se de uma perspectiva que compreenda o princípio da igualdade como direito à diferença.

Acabam, assim, restringindo as possibilidades da hermenêutica jurídica, indo contra o espírito de democratização expresso na Constituição, fruto de longas lutas sociais dos povos de santo e outros grupos subalternizados. Somente um movimento inverso, que explicite, dê voz e reconheça as diversas histórias negadas e violentadas durante o processo civilizatório brasileiro, poderá contribuir para a diminuição do estrutural quadro 
de desigualdade e ausência de direitos de determinados grupos.

O primeiro passo, portanto, é romper o silêncio e trazer, expressamente, as religiões de matriz africana como beneficiárias da imunidade tributária, reconhecendo-as como parte do patrimônio histórico-cultural brasileiro. Passo esse que, pela sua transparência e simplicidade, já demorou tempo demais a ser dado. O segundo é concluir que os direitos de liberdade religiosa desse grupo, para serem exercidos plenamente, necessitam de políticas públicas e modelos institucionais que garantam e promovam a construção de espaços de reconhecimento, diferentemente do que requerem as demais religiões.

\title{
THE SILENCE OF THE JURISTS: THE TAX IMMUNITY ON THE TEMPLE OF ANY CULT AND THE RELIGIONS OF AFRICAN MATRIX IN LIGHT OF THE CONSTITUTION OF 1988
}

\begin{abstract}
The present paper analyze the jurist discourses, through legal writings and decisions from higher Brazilian courts, about the tax immunity on worships temples of any religion having in mind the practices of religions of African origin. The research material was raised by the search on sites of higher Brazilian courts, which are the Superior Court of Justice and the Supreme Court, and most of manuals of a legal nature. Through this analyze, it attempts to understanding how the silent of the legal experts contributes to maintain the social and historical inequality against black expressions in Brazil. Within this context, it is made a reflection about how these judicial stands distances themselves from innovations brought by the Constitution of 1988 in the case of legal hermeneutic. Finally, it will be seen that the Brazilian decision system still tagged by the persecution against the black people, persecution that must be broken, in order to give visibility to the practices of the black culture, breaking the silence that exists and making effective the constitutional guarantees.
\end{abstract}

Keywords: tax immunity; worships temples of any religion; religions of African origin; Constitution of 1988; racism.

\section{REFERÊNCIAS BIBLIOGRÁFICAS}

AGAMBEN, Giorgio. O que é o contemporâneo? e outros ensaios. Trad. Vinícius Nicastro Honesko. Chapecó: Editora Argos, 2009.

AMARO, Luciano. Direito Tributário Brasileiro. 17ª Edição. São Paulo: Saraiva, 2011.

AZEVEDO, Celia M. M. de. Onda negra, medo branco: o negro no imaginário das elites - século XIX. Rio de Janeiro: Paz e Terra, 2004.

BASTOS, Celso Ribeiro. Curso de direito financeiro e de direito tributário. São Paulo: Saraiva, 2001. 
BERNARDINO-COSTA, Joaze. Saberes subalternos e decolonialidade: os sindicatos das trabalhadoras domésticas no Brasil. Brasília: Editora Universidade de Brasília, 2015.

BERNARDO, Augusto Sérgio dos Santos S. Identidade Racial e Direito à Diferença Xangô e Thémis. Dissertação de mestrado. Brasília: UnB, 2006.

BERTÚLIO, Dora Lúcia de Lima. Direito e Relações Raciais: uma introdução crítica ao racismo. Dissertação de mestrado. Florianópolis: UFSC, 1989.

BOURDIEU, Pierre. O Poder Simbólico. Rio de Janeiro: Bertrand Brasil, 2010.

BRASIL. Constituição (1988). Constituição da República Federativa do Brasil. Brasília, 1988. Disponível em: <http://www.planalto.gov.br/ccivil_03/Constituicao/Constituicao.htm>. Acesso em: 20 maio 2016.

Consultoria Legislativa da Câmara dos Deputados, 2013. MARTON, Ronaldo Lindimar José. A Imunidade Tributária dos Templos de Qualquer Culto na Interpretação da Constituição Adotada pelo Supremo Tribunal Federal. Fevereiro, 2013.

Supremo Tribunal Federal. Recurso Extraordinário no 325.822/SP. Rel. Min. Ilmar Galvão, Tribunal

Pleno, Brasilia, DF, 14 mai. 2004. Disponível em:
<http://redir.stf.jus.br/paginadorpub/paginador.jsp?docTP=AC\&docID=260872>. Acesso em: 3março 2016.

Supremo Tribunal Federal. Recurso Extraordinário no 562.351/RS. Rel. Min. Ricardo Lewandowski,

Primeira Turma, Brasília, DF, 13 dez. 2012. Disponível em: <http://redir.stf.jus.br/paginadorpub/paginador.jsp?docTP=TP\&docID=3195619>. Acesso em: 3 março 2016.

CARRAZZA, Roque Antonio. Curso de Direito Constitucional Tributário. 26a Edição. Malheiros Editores, 2010.

CARVALHO, Paulo de Barros. Curso de Direito Tributário. 21ª Ed. São Paulo: Saraiva, 2009.

COÊLHO, Sacha Calmon Navarro. Curso de Direito Tributário Brasileiro. Ed. Forense. Rio de Janeiro, 2009.

COSTA, Regina Helena. Imunidades Tributárias: teoria e análise da jurisprudência do STF. São Paulo: Malheiros Editores, 2001.

DERRIDA, Jacques. Força de Lei: o fundamento místico da autoridade. Trad. Leyla Perrone-Moisés. São Paulo: Editora WMF Martins Fontes, 2010.

DUARTE, Evandro C. Piza. Criminologia e Racismo. Introdução ao processo de recepção das teorias criminológicas no Brasil. Dissertação de Mestrado em Direito pela Universidade Federal de Santa Catarina UFSC. Florianópolis, 1998.

Do Medo da Diferença à Liberdade com Igualdade: As Ações Afirmativas para Negros no Ensino Superior e os Procedimentos de Identificação de seus Beneficiários. Tese de Doutorado em Direito pela Universidade de Brasília - UnB. Brasília, 2011.

DUARTE, Evandro C. Piza e CARVALHO NETTO, Menelick. A indeterminação dos conceitos nas políticas de acesso ao Ensino Superior. In: COSTA, Hilton; PINHEL, André; SILVEIRA, Marcos Silva. Uma década de políticas afirmativas: panorama, argumentos e resultados. Ponta Grossa: Editora UEPG, 2012.

DUARTE, Evandro C. Piza e QUEIROZ, Marcos Vinícius Lustosa. Para inglês ver: a cidadania na Constituinte Brasileira de 1823 e as tensões sociais do Império Português no Atlântico Negro. Braślia, 2011 (no prelo). 
DUSSEL, Enrique. 1492: o encobrimento do outro: a origem do mito da modernidade: Conferências de Frankfurt. Enrique Dussel; tradução Jaime A. Clasen Petrópolis, RJ: Vozes, 1993.

FANON, Frantz. Pele Negra, Máscaras Brancas. Trad. Renato da Silveira. Salvador: EDUFBA, 2008.

FLAUZINA, Ana Luiza Pinheiro. Corpo negro caído no chão: o sistema penal e o projeto genocida do estado brasileiro. Dissertação de Mestrado em Direito pela Universidade de Brasília - UnB. Brasília, 2006.

FOUCAULT, Michel. A Ordem do Discurso. 13ª Ed. São Paulo: Edições Loyola, 2006.

GILROY, Paul. O Atlântico Negro. Trad. Cid Knipel Moreira. 2a Ed. SP: 34, 2012.

GUIMARÃES, Andréa Letícia Carvalho. ĖTÓ FÚN AWÓN TÓ YÀTÖ: análise do I Plano Nacional de inclusão dos Povos e Comunidades Tradicionais de Matriz Africana a partir dos processos de reconstrução da identidade do sujeito constitucional. Dissertação de Mestrado em Direito pela Universidade de Brasília - UnB. Brasília, 2014.

HALL, Stuart. Da diáspora: Identidades e mediações culturais. Organização Liv Sovik; Tradução Adelaine La Guardia Resende ... [et all]. BH: UFMG, 2013.

HASLANGER, Sally. Opressão Racial e Outras. In: LEVINE, Michael e PATAKI, Tamas (orgs). Racismo em Mente. Trad. Fábio Assunção Lombardi Rezende. São Paulo: Madras, 2005.

IPHAN. Terreiros do Distrito Federal e Entorno: Inventário Nacional de Referências Culturais. Superintendência do Iphan no Distrito Federal. Coordenação de GiorgeBessoni, Rodrigo Ramassote e Marcelo Reis. Textos de Marcelo Reis... [et al.]. Brasília: Iphan-DF, 2012.

LODY, Raul. O povo do santo: religião, história e cultura dos orixás, voduns, inquices e caboclos. Rio de Janeiro: Pallas, 1995.

MACHADO, Hugo de Brito. Curso de Direito Tributário. 32a Edição. Malheiros Editores, 2011.

MARIANO. Ricardo. Laicidade à brasileira: católicos, pentecostais e laicos em disputa na esfera pública. In: Civitas. Porto Alegre, v. 11, n. 2, p. 238-258, mai-ago. 2011.

MARTON, Ronaldo Lindimar José. A Imunidade Tributária dos Templos de Qualquer Culto na Interpretação da Constituição adotada pelo Supremo Tribunal Federal. Brasilia: Consultoria Legislativa da Câmara dos Deputados, 2013.

MEIRELLES, Hely Lopes. Direito Municipal Brasileiro. 10a Edição. São Paulo: Malheiros Editores, 1998.

MELLO, Celso Antônio Bandeira de. O Conteúdo Jurídico do Princípio da Igualdade. São Paulo: Malheiros Editores, 2010.

MENDES, Gilmar Ferreira; BRANCO, Paulo Gustavo Gonet. Curso de Direito Constitucional. 6a Ed. São Paulo: Saraiva, 2011.

MORAES, Alexandre de. Direito Constitucional 23ª Ed. São Paulo: Atlas, 2008. 
MOURA, Clóvis. Rebeliões da Senzala. RS: Mercado Aberto, 1988.

NASCIMENTO, Abdias do. O Genocídio do Negro Brasileiro: processo de um racismo mascarado. RJ: Ed. Paz e Terra, 1978.

PARÉS, Luis Nicolau. A Formação do Candomblé: história e ritual da nação jeje na Bahia. 2a Edição. Campinas, SP: Editora da Unicamp, 2007.

PIOVESAN, Flávia. A Compatibilidade das Cotas Raciais com a Ordem Internacional e com a Constituição Brasileira. In: Audiência Pública sobre Cotas para Afro-descendentes nas Universidades - ADPF 186 e Recurso Extraordinário 597.285/RS, 2010. Disponível em: http://www.stf.jus.br/arquivo/cms/processoAudienciaPublicaAcaoAfirmativa/anexo/cotasSTF2010rev1_Flavi a_Piovesan.doc. Acesso em 25/09/2016.

SÁ, Gabriela Barreto. O crime de reducir pessoa livre à escravidão nas Casas de Morada da Justiça no Rio Grande do Sul (1835-1874). Dissertação de Mestrado. Florianópolis: UFSC, 2013.

SABBAG, Eduardo. Manual de Direito Tributário. 3ª Ed. São Paulo: Saraiva, 2014.

SOVIK, LIV. Aqui ninguém é branco: hegemonia branca e media no Brasil. In: WARE, Vron. Branquidade: identidade branca e multiculturalismo. RJ: Garamond, 2004.

SOUZA, André Ricardo de. O Estado Frente às Práticas Econômico-assistenciais de Grupos religiosos no Brasil e Outros Países Latino-americanos. Acta Científica XXIX Congreso de laAsociaciónLatinoamericana de Sociología, GT-21, 2013.

TORRES, Ricardo Lobo. Curso de direito financeiro e tributário. Rio de Janeiro: Renovar, 2010.

Trabalho enviado em 01 de julho de 2016.

Aceito em 09 de outubro de 2016. 